\title{
Local Breast Cancer Recurrence after Mastectomy and Breast-Conserving Surgery for Paget's Disease: A Meta-Analysis
}

\author{
Yu-Jie Li ${ }^{\mathrm{a}} \quad$ Xiao-E Huang ${ }^{\mathrm{b}} \quad$ Xiao-Dong Zhou ${ }^{\mathrm{b}}$ \\ a Department of Surgical Oncology, Ningbo No. 2 Hospital of Zhejiang Province, China \\ ${ }^{b}$ Department of Surgical Oncology, Yuyao People's Hospital of Zhejiang Province, China
}

\section{Keywords}

Paget's disease of the breast - Mastectomy .

Breast-conserving surgery · Meta-analysis

\section{Summary}

Background: Paget's disease (PD) of the breast is a rare presentation of breast malignancy. Mastectomy has been considered the standard of care, but several studies have shown that breast-conserving surgery (BCS) with radiotherapy is an alternative option. According to the literature, the total recurrence rate is as high as 20$40 \%$. In an effort to enable a rational therapy decision, we compiled and analyzed the available data on PD. Methods: Pubmed, Web of Knowledge, and China Journal Net were searched for studies concerning treatment for PD between 1990 and 2013. A meta-analysis was performed to compare the effect of different treatments. Results: 7 studies with a total of 685 patients were included. The cumulative local recurrence rate was $7.6 \%, 5.6 \%$ among women undergoing mastectomy and $13.2 \%$ among those treated with BCS. Compared to the BCS group, mastectomy showed significant differences in terms of local recurrence (odds ratio $=0.38,95 \%$ confidence interval $0.21-0.69 ; p=0.001$ ). Conclusion: Since not all currently available diagnostic and therapeutic options (magnetic resonance imaging, radiotherapy, tamoxifen) were systematically used in the studies included in this meta-analysis, it may be presumptuous to suggest that mastectomy is the right choice for all patients with PD in a modern interdisciplinary setting. Rather we can conclude that all efforts should be undertaken to assure local control since BCS is not equivalent to mastectomy in the treatment of PD.

\section{Introduction}

Paget's disease (PD) of the breast was first described in 1856 by Velpeau [1] as an uncommon entity. PD is an infrequent presentation of breast malignancy, which is often associated with ductal carcinoma in situ (DCIS) and/or invasive cancer, and accounts for $1-3 \%$ of all the breast tumors [2]. The clinical appearance of PD of the breast is often described as a pigmented, erythematous, weeping, or crushed lesion with irregular borders. PD is often mistaken for a benign dermatologic disease involving the nipple. Mammography may depict a mass or calcification representative of invasive cancer or DCIS, but has limited power to detect underlying DCIS with PD. Magnetic resonance imaging (MRI) is more sensitive than mammography in detecting multicentric breast cancer [3]. Mastectomy has long been considered as definitive treatment for PD. However, some studies have shown that breast-conserving surgery (BCS) is a feasible option in selected patients. BCS has demonstrated similar long-term survival rates in follow-up studies, with approximately $5 \%$ risk for local recurrence in 5 years [4]. The purpose of this study was to compile and analyze the available data evaluating the outcomes of different surgical treatments in patients with PD, with special emphasis on local recurrence.

\section{Methods}

Literature Search

PubMed, Web of Knowledge, and China Journal Net were searched for studies on PD published between January 1990 and December 2013, without language restrictions. The search terms used were 'Paget's disease of breast', 'recurrence' and 'treatment'. The reference lists of the relevant studies were checked manually for any additional studies.

\section{KARGER \\ Fax +497614520714 \\ Information@Karger.com}

www.karger.com (c) 2014 S. Karger GmbH, Freiburg

$1661-3791 / 14 / 0096-0431 \$ 39.50 / 0$

Accessible online at:

www.karger.com/brc
Dr. Yu-Jie Li

Department of Surgical Oncology

Ningbo No. 2 Hospital

Ningbo, Zhejiang Province, 315040, China

liyujie24@gmail.com 


\section{Study Selection}

Studies which met the following inclusion criteria were included in the meta-analysis: i) patients diagnosed with PD of the breast without metastasis; ii) controlled trial; iii) patients treated with mastectomy or BCS; and iv) reports available on 1 or more of the following primary or secondary outcomes: overall survival, disease-free survival, recurrence-free survival, and local recurrence.

\section{Data Extraction}

Data was extracted by 2 of the authors (LYJ and HXE). The following data was gathered for each eligible trial: authors' names, year of publication, trial design, patient eligibility criteria, baseline patient characteristics, age range, clinical tumor stage, clinical node stage, and end points.

\section{Statistical Analysis}

Although the fixed effects and random effects models yielded similar conclusions, many investigators consider the random effects model to be a more natural choice than the fixed effects model in a medical decisionmaking context $[5,6]$. A random effects model was used to calculate a pooled odds ratio (OR) with its $95 \%$ confidence interval (CI) for local recurrence. Statistical analyses were carried out using Cochrane Review Manager 5.0 software. Heterogeneity was explored using $\mathrm{I}^{2}$ statistics, a measure of how much the variance between studies, rather than chance, can be attributed to inter-study differences. $\mathrm{I}^{2}>50 \%$ was regarded to indicate strong heterogeneity.

\section{Results}

We identified 157 potentially relevant articles (fig. 1). After exclusion of duplicate references, non-relevant literature, and those studies that did not satisfy the inclusion criteria, 23 candidate articles were considered for the meta-analysis. After careful review of the full text of these articles, 7 studies were included. The study characteristics are summarized in tables 1 and 2 .

Patient demographics for the 7 studies are presented in table 1. All papers were retrospective chart reviews. The year of publication ranged from 1999 to 2010. Study sizes ranged from 45 to 212 patients. 1 study [7] investigated the role of MRI in evaluating patients with a diagnosis of $\mathrm{PD}$, and another 2 studies $[8,9]$ reported the use of tamoxifen. The majority of the studies had local recurrence as the primary outcome.

The total patient population for these 7 studies, was 503 in the mastectomy group and 182 in the BCS group. There were no significant heterogeneities among the 7 retrospective studies $\left(\mathrm{p}\right.$ for $\mathrm{Q}$ statistics $=0.31, \mathrm{I}^{2}=16 \%$ ). The pooled OR for local recurrence was 0.38 (95\% CI 0.21-0.69) (fig. 2). Mastectomy faired significantly better than BCS in terms of the frequency of local recurrence $(\mathrm{p}=0.001)$.

\section{Discussion}

PD is often mistaken for a benign dermatologic condition such as dermatitis of the nipple. A skin biopsy of the eczematous area should be obtained to exclude or confirm the diagnosis of PD. Once a patient has a confirmed diagnosis of PD, further imaging should be undertaken to evaluate whether there is an underlying invasive or non-invasive carcinoma. Since ultrasound and mammography are not specific enough to detect multifocal and/or multicentric disease, MRI may be helpful. According to several studies, MRI was highly sensitive in detecting invasive cancer in patients with $\mathrm{PD}$, even if ultrasound and mammography showed negative results [7, 10, 11].

The surgical treatment of PD has been controversial. Historically, mastectomy with or without axillary lymph node dissection has been the standard therapy, and this approach was supported by the observation that there was almost always an underlying invasive or non-invasive carcinoma. With the increasing diagnosis of early breast cancers and the findings from multiple randomized prospective trials, BCS has been demonstrated to be a feasible alternative for patients with dis-

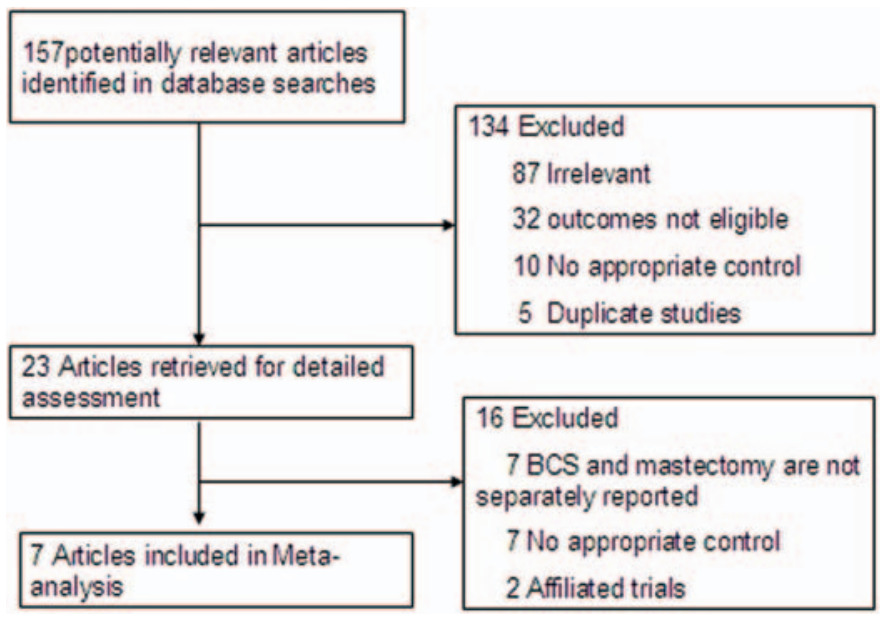

Fig. 1. Flowchart of the results of the literature search.
Fig. 2. Forest plot presenting the pooled odds ratios of systemic recurrence for mastectomy versus breast conserving surgery.

\begin{tabular}{|c|c|c|c|c|c|c|c|c|}
\hline Studv or Subgroup & \multicolumn{2}{|c|}{ Mastectomy } & \multicolumn{2}{|c|}{ Conserving surgery } & Weight & $\begin{array}{l}\text { Odds Ratio } \\
\text { M.H, Fixed, } 95 \% \mathrm{Cl}\end{array}$ & \multicolumn{2}{|c|}{$\begin{array}{c}\text { Odds Ratio } \\
\text { M.H, Fixed, } 95 \% \text { CI }\end{array}$} \\
\hline Caliskan2008 & 1 & 71 & 6 & 43 & $22.8 \alpha$ & $0.09[0.01,0.76]$ & & \\
\hline Dalberg2008 & 15 & 169 & 7 & 43 & $31.5 \%$ & $0.50[0.19,1.32]$ & & \\
\hline Oxon1991 & 2 & 37 & 4 & 10 & $18.5 \%$ & $0.09[0.01,0.58]$ & & \\
\hline Joseph 2007 & 3 & 21 & 3 & 24 & $7.4 \%$ & $1.17[0.21,6.51]$ & & \\
\hline lawase 2005 & 3 & 92 & 1 & 12 & $5.3 \alpha$ & $0.37[0.04,3.88]$ & & \\
\hline Siponen2010 & 0 & 39 & 1 & 19 & $6.1 \%$ & $0.16[0.01,4.02]$ & & \\
\hline Sutton 1999 & 4 & 74 & 2 & 31 & $8.3 x$ & $0.83[0.14,4.78]$ & & \\
\hline Total $(95 \% \mathrm{Cl})$ & & 503 & & 182 & $1000 \%$ & $0.38[021.0 .69]$ & & \\
\hline Total events & 28 & & 24 & & & & & \\
\hline $\begin{array}{l}\text { Heterogeneity. } \mathrm{Chi}^{\mathrm{x}}= \\
\text { Test for overall effect }\end{array}$ & $\begin{array}{l}.12 . d f=6 \\
Z=3.20(P\end{array}$ & $\begin{array}{l}(P=0 \\
=0.001\end{array}$ & $\begin{array}{l}\text { 31); } F=16 \gamma \\
\text { 1) }\end{array}$ & & & & $\begin{array}{lc}001 & 1 \\
0.1 & 1 \\
\text { Mastectomy } & 1\end{array}$ & $\begin{array}{r}10 \\
\text { Conserv }\end{array}$ \\
\hline
\end{tabular}


Table 1. Overview of the reviewed studies

\begin{tabular}{|c|c|c|c|c|c|c|}
\hline Author, year [ref.] & Country & Patients, $\mathrm{n}$ & Mean age, years & Study design & $\begin{array}{l}\text { MRI use, } \\
\%\end{array}$ & $\begin{array}{l}\text { Median follow-up, } \\
\text { months }\end{array}$ \\
\hline Dixon et al., 1991 [2] & UK & 47 & 62 & $\begin{array}{l}\text { retrospective } \\
\text { review }\end{array}$ & - & M: 40 / BCS: 56 \\
\hline Sutton et al., 1999 [8] & UK & 105 & M: 57.7 / BCS: 57.1 & $\begin{array}{l}\text { retrospective } \\
\text { review }\end{array}$ & - & M: 84 / BCS: 60 \\
\hline Dalberg et al., 2007 [9] & Sweden & 212 & 70 & $\begin{array}{l}\text { retrospective } \\
\text { review }\end{array}$ & - & 144 \\
\hline Caliskan et al., 2008 [14] & Italy & 114 & 54 & $\begin{array}{l}\text { retrospective } \\
\text { review }\end{array}$ & - & 73 \\
\hline Joseph et al., 2007 [15] & USA & 45 & - & $\begin{array}{l}\text { retrospective } \\
\text { review }\end{array}$ & - & M: 82.5 / BCS: 90 \\
\hline Kawase et al., 2005 [16] & USA & 104 & 57 & $\begin{array}{l}\text { retrospective } \\
\text { review }\end{array}$ & - & 84 \\
\hline Siponen et al., 2010 [7] & Finland & 58 & 64 & $\begin{array}{l}\text { retrospective } \\
\text { review }\end{array}$ & 24.1 & 52 \\
\hline
\end{tabular}

MRI = Magnetic resonance imaging; $\mathrm{M}=$ mastectomy; $\mathrm{BCS}=$ breast-conserving surgery.

Table 2. Overview of the reviewed studies

\begin{tabular}{|c|c|c|c|c|c|c|}
\hline \multirow[t]{2}{*}{ Author, year [ref.] } & \multirow[t]{2}{*}{$\begin{array}{l}\text { Study } \\
\text { duration }\end{array}$} & \multirow[t]{2}{*}{ Patient source } & \multirow[t]{2}{*}{ Radiotherapy, \% } & \multirow[t]{2}{*}{$\begin{array}{l}\text { Tamoxifen, } \\
\%\end{array}$} & \multicolumn{2}{|c|}{$\begin{array}{l}\text { Histological findings of } \\
\text { relapses, } \mathrm{n}\end{array}$} \\
\hline & & & & & invasive & $\begin{array}{l}\text { non- } \\
\text { invasive }\end{array}$ \\
\hline Dixon et al., 1991 [2] & 1973-1989 & City Hospital, Nottingham & - & - & $\begin{array}{l}\text { M: } 2 \\
\text { BCS: } 3\end{array}$ & BCS: 1 \\
\hline Sutton et al., 1999 [8] & 1975-1997 & The Royal Marsden Hospital & $\begin{array}{l}\text { M:4.1 } \\
\text { BCS:45.2 }\end{array}$ & $\begin{array}{l}\text { M: } 14.9 \\
\text { BCS: } 19.4\end{array}$ & $\begin{array}{l}\text { M: } 2 \\
\text { BCS: } 1\end{array}$ & $\begin{array}{l}\text { M: } 2 \\
\text { BCS: } 1\end{array}$ \\
\hline Dalberg et al., 2007 [9] & 1976-2001 & $\begin{array}{l}2 \text { regional Breast Cancer } \\
\text { Registries: Stockholm-Gotland, } \\
\text { Uppsala-Orebro }\end{array}$ & $\begin{array}{l}\text { M:9 } \\
\text { BCS:19 }\end{array}$ & 12.0 & - & - \\
\hline Caliskan et al., 2008 [14] & 1996-2003 & $\begin{array}{l}\text { European Institute of Oncology, } \\
\text { Milan, Italy }\end{array}$ & $\begin{array}{l}\text { M:5.6 } \\
\text { BCS:81.4 }\end{array}$ & - & $\begin{array}{l}\text { M: } 1 \\
\text { BCS: } 4\end{array}$ & BCS: 2 \\
\hline Joseph et al., 2007 [15] & 1990-1997 & $\begin{array}{l}\text { Columbia University Medical } \\
\text { Center }\end{array}$ & - & - & - & - \\
\hline Kawase et al., 2005 [16] & 1949-1993 & M.D. Anderson Cancer Center & $\begin{array}{l}\text { M:19.6 } \\
\text { BCS:100 }\end{array}$ & - & - & - \\
\hline Siponen et al., 2010 [7] & 1995-2006 & $\begin{array}{l}\text { Breast Surgery Unit of Helsinki } \\
\text { University Central Hospital }\end{array}$ & $\begin{array}{l}\text { M:38.5 } \\
\text { BCS:26.3 }\end{array}$ & - & - & BCS: 1 \\
\hline
\end{tabular}

$\mathrm{M}=$ Mastectomy; $\mathrm{BCS}=$ breast-conserving surgery.

ease limited to the central segment of the breast $[12,13]$. The reported techniques for BCS in patients with PD vary widely and include nipple excision and central segmentectomy as well as these resections plus radiation. There is a place for BCS in selected patients with PD of the breast, especially those with no mass.
Dixon et al. [2] reported a high recurrence rate of $40 \%$ in patients treated with local excision alone, whose mammograms suggested in situ changes confined to the nipple area. Polar et al. [12] reported a local recurrence rate of $33.3 \%$ with a median follow-up time of 6 years in 33 patients treated with local excision alone with or without underlying DCIS con- 
fined to the nipple areola complex; they concluded that local excision alone was not an appropriate treatment for patients with PD of the nipple. Conversely, Bijker et al. [4] reported that $\mathrm{BCS}$ plus radiotherapy can definitely reduce the local recurrence rate $(6.6 \%)$, and concluded that PD of the nipple cannot be treated successfully with BCS alone; radiotherapy was mandatory after BCS to maintain adequate local control. 2 studies [9, 14] noticed that patients with PD were more likely to be estrogen receptor (ER)- and progesterone receptor (PR)-negative, and only a small proportion of ER- and PR-positive patients were treated with tamoxifen after surgery.

Our study was a systematic review of the available literature examining local recurrence in patients with PD undergoing mastectomy or BCS. The local recurrence rate was $5.6 \%$ in the mastectomy group (28/503) and $13.2 \%$ in the BCS group (24/182). With the limitations inherent in retrospective reviews, case control studies, and case series, our review found that local recurrence rates were higher in patients that underwent BCS with or without radiotherapy (fig. 2). 4 of our 7 studies mentioned histological findings for relapses $(\mathrm{n}=13$ invasive, $\mathrm{n}=7$ non-invasive). It appeared that relapsed patients tended to develop invasive breast carcinoma, and invasive recurrence was associated with poor prognosis after BCS in patients with $\mathrm{PD}$ of the nipple $[2,14]$.

There are some limitations to our study. First, most of the included studies were single-center retrospective chart reviews with inherent limitations such as selection bias and inaccurate or missing data reports. Hence, our findings must be interpreted with caution. To date, no randomized controlled trial has been completed to evaluate BCS for PD. The heterogeneity between studies with respect to the type of mastec- tomy and BCS may have been a source of study bias, as we were unable to analyze these factors independently based on the data reported.

In summary, our meta-analysis reviewed much of the literature published to date, and demonstrated that BCS is not a reasonable option for women. Further research must be performed with adequate reporting of recurrence based on stage and 5-year disease-free survival, which would then allow clinicians to better council patients about BCS for PD.

\section{Conclusion}

This meta-analysis illustrates that breast cancer recurrence rates with BCS do not compare to those achieved with mastectomy. Since not all currently available diagnostic and therapeutic options (MRI, radiotherapy, tamoxifen) were systematically used in the studies included in this meta-analysis, it may be presumptuous to suggest that mastectomy is the right choice for all patients with PD in a modern interdisciplinary setting. Rather we can conclude that all efforts should be undertaken to assure local control since BCT is not equivalent to mastectomy in the treatment of PD. Further prospective randomized studies with long-term follow-up are required to validate the results of this meta-analysis.

\section{Disclosure Statement}

The authors did not provide a disclosure statement.

\section{References}

1 Velpeau S: A Treatise on Diseases of the Breast and Mammary Region. London, Sydenham Society, 1856, p. 3.

2 Dixon AR, Galea MH, Ellis IO, et al.: Paget's disease of the nipple. Br J Surg 1991;78:722-3.

$\checkmark 3$ Bagley FH: The role of magnetic resonance imaging mammography in the surgical management of the index breast cancer. Arch Surg 2004;139:380-3.

4 Bijker N, Rutgers EJ, Duchateau L, et al.: Breastconserving therapy for Paget disease of the nipple: a prospective European Organization for Research and Treatment of Cancer study of 61 patients. Cancer 2001;91:472-7.

5 DerSimonian R, Laird N: Meta-analysis in clinical trials. Control Clin Trials 1986;7:177-88.

6 Ades AE, Lu G, Higgins JP: The interpretation of random-effects meta-analysis in decision models. Med Decis Making 2005;25:646-54.
7 Siponen E, Hukkinen K, Heikkilä P, et al.: Surgical treatment in Paget's disease of the breast. Am J Surg 2010;200:241-6.

8 Sutton RJ, Singh A, Baker CB, et al.: Is mastectomy overtreatment for Paget's disease of the nipple? Breast 1999;8:191-4.

9 Dalberg K, Hellborg H, Wärnberg F: Paget's disease of the nipple in a population based cohort. Breast Cancer Res Treat 2008;111:313-9.

10 Frei KA, Bonel HM, Pelte MF, et al.: Paget's disease of the breast: findings at magnetic resonance imaging and histopathologic correlation. Invest Radiol 2005;40:363-7.

11 Capobianco G, Spaliviero B, Dessole S, et al.: Paget's disease of the nipple diagnosed by MRI. Arch Gynecol Obstet 2006;274:316-8.

12 Polgár C, Orosz Z, Kovács T, et al.: Breast-conserving therapy for Paget disease of the nipple: a prospective European Organization for Research and Treatment of Cancer study of 61 patients. Cancer. 2002 Mar 15;94(6):1904-5.
13 Veronesi U, Cascinelli N, Mariani L, et al.: Twenty-year follow-up of a randomized study comparing breast-conserving surgery with radical mastectomy for early breast cancer. N Engl J Med 2002;347: 1227-32.

14 Caliskan M, Gatti G, Sosnovskikh I, et al.: Paget's disease of the breast: the experience of the European Institute of Oncology and review of the literature. Breast Cancer Res Treat 2008;112:513-21.

15 Joseph KA, Ditkoff BA, Estabrook A, et al.: Therapeutic options for Paget's disease: a single institution long-term follow-up study. Breast J 2007;13: 110-1.

16 Kawase K, Dimaio DJ, Tucker SL, et al.: Paget's disease of the breast: there is a role for breast-conserving therapy. Ann Surg Oncol 2005;12:391-7. 